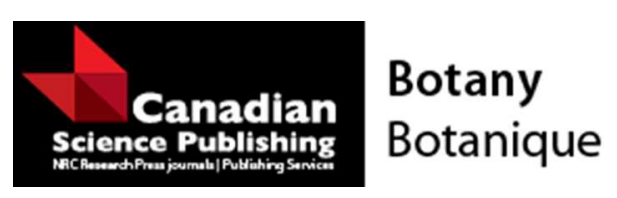

\title{
The significance of shared leaf shape in Alseuosmia pusilla and Pseudowintera colorata
}

\begin{tabular}{|r|l|}
\hline Journal: & Botany \\
\hline Manuscript ID & cjb-2016-0049.R1 \\
\hline Danuscript Type: & Article \\
\hline Complete List of Authors: & $\begin{array}{l}\text { Yager, Karl; Victoria University of Wellington, School of Biological Sciences } \\
\text { Schaefer, H. Martin; University Freiburg, Department of Evolutionary } \\
\text { Biology and Animal Ecology } \\
\text { Gould, Kevin; Victoria University of Wellington, School of Biological } \\
\text { Sciences }\end{array}$ \\
\hline Keyword: & $\begin{array}{l}\text { Batesian mimicry, herbivory, leaf shape, phenotypic plasticity, visual leaf } \\
\text { signalling }\end{array}$ \\
\hline & \\
\hline
\end{tabular}

\section{SCHOLARONE ${ }^{\text {wN }}$ \\ Manuscripts}


The significance of shared leaf shape in Alseuosmia pusilla and Pseudowintera colorata

Karl G. Yager ${ }^{\mathrm{a} \dagger}$, H. Martin Schaefer ${ }^{\mathrm{b}}$, Kevin S. Gould ${ }^{\mathrm{a}^{*}}$

${ }^{a}$ School of Biological Sciences, Victoria University of Wellington, PO Box 600, Wellington 6140, New Zealand.

${ }^{\mathrm{b}}$ Department of Evolutionary Biology and Animal Ecology, Faculty of Biology, University of Freiburg, Hauptstrasse 1, D-79104, Freiburg, Germany.

* Corresponding author: Kevin S. Gould. Phone: +64 4463 6649. Fax: +64 4463 5331. Email: kevin.gould@vuw.ac.nz

${ }^{\dagger}$ E-mail: karl.yager@vuw.ac.nz

"E-mail: martin.schaefer@biologie.uni-freiburg.de 


\begin{abstract}
Leaf shape, size and colour are used by herbivores to identify sources of palatable foliage for food. It is possible, therefore, that an undefended plant might gain protection from herbivores by matching leaf characteristics of a chemically-defended species. We demonstrate the use of a geometric morphometric approach to quantify spatial variation in leaf shape and size across populations of Pseudowintera colorata, and a putative Batesian mimic, Alseuosmia pusilla.
\end{abstract}

These are unrelated, sympatric species which, to the human eye, bear strikingly similar foliage. Using the Cartesian coordinates of leaf margins as descriptors of leaf shape, we found that in the chemically-defended $P$. colorata, leaves were morphologically distinct from all neighbouring species except for the undefended A. pusilla. A. pusilla individuals were more similar to neighbouring than to distant $P$. colorata, and $90 \%$ of leaf shape variation in the two species varied similarly across an altitudinal gradient. The data are consistent with Batesian mimicry, wherein the conspicuous characteristic of a defended model is replicated by an undefended mimic across its entire growing range. Our study provides the first detailed and powerful quantitative leaf shape evidence of leaf shape being matched between an undefended plant species to a chemically-defended unrelated species across a shared growing range, and highlights the importance of using a spatially explicit morphometric method when investigating leaf shape, especially in relation to plant mimicry.

Key words: Batesian mimicry, herbivory, leaf shape, visual leaf signalling, phenotypic plasticity 


\section{Introduction}

Many plant species exhibit morphological plasticity in response to ontogenetic, abiotic, competitive, and predatory pressures. These traits often fluctuate predictably across environmental gradients, suggesting that phenotypic plasticity confers a selective advantage to a plant in its natural habitat (Hovenden and Vander Schoor 2006, Royer et al. 2009). Leaf morphology, for example, assists in temperature regulation (Gurevitch and Schuepp 1990, Hegazy and El Amry 1998, Roth-Nebelsick 2001) and light interception (Horn 1971, Tsukaya 2005); it can also serve to minimise wind damage (Anten et al. 2010), to tolerate salinity (Sinclair and Hoffmann 2003), drought, or nutrient deficiencies (Cunningham et al. 1999, Leigh et al. 2011), or to deter predation by herbivores (Niemelä and Tuomi 1987, Brown and Lawton 1991). Within these broader trends, however, there is often considerable intraspecific variation in leaf shape even in the same environment (McDonald et al. 2003, Nicotra et al. 2011). The possible functional significance of such variation is usually far from clear.

Amidst this background of morphological heterogeneity, there are examples in which variation in the leaf shape, size and colour of one species correlates closely with that in another, unrelated species. For example, the non-spiny leafed Celmisia petriei and C. lyallii from New Zealand look like spiny members of the genus Aciphylla (Brown and Lawton 1991), whilst the non-stinging nettle like group of plants containing species from across several genera (Lamium album, L. purpureum, Lamiastrum galeobdolon, Ballota nigra, Galeopsis spp.), commonly known as dead nettles due to their lack of sting, resemble the defended European stinging nettle (Urtica dioica) (Brown and Lawton 1991, Wheeler 2004). In other cases, this correlation of resemblance only seems to occur in the presence of a 
particular species. In the heavily grazed desert/steppe transition zone of the northern Negev, Israel, the leaf form and overall habit of the hill ecotype of Iris atrofusca appears to be more similar to that of the unpalatable Asphodelus ramosus, than to the valley ecotype growing in the absence of $A$. ramosus (Shimshi 1979). Leaves on the woody vine Boquila trifoliolata of southern Chile, bear striking physical resemblance to those on their host tree; when portions of the vine traverse other hosts, their leaf shape changes accordingly (Gianoli and CarrascoUrra 2014). Similarly, the leaves of some Australian mistletoes closely resemble those of their host plants (Barlow and Wiens 1977, Canyon and Hill 1997). In those instances the convergence in leaf shape has been hypothesised to present a potential fitness advantage by using mimicry to evade detection by herbivores. Leaf shape is known to influence the consumption, performance, and ovipositing choices of insect herbivores, and thus may provide a visual cue of a plant's palatability (Rausher 1978, Mackay and Jones 1989, RiveroLynch et al. 1996, Campitelli et al. 2008).

Successful plant mimicry requires that the mimic and model converge in the perceptual world of an approaching herbivore such that it cannot easily distinguish between the two (Schaefer and Ruxton 2009). It needs to be demonstrated, therefore, that leaf shape, size and colour of the putative mimic do indeed overlap with the ranges of those of the model, and that any morphological convergence is more evident between individuals where the two species cooccur. Previous studies of mimicry in vegetative shoots have relied on 'traditional' measures such as leaf length, width, area, and numbers of lobes, which, although useful as broad descriptors of morphology, cannot resolve subtle differences in shape that might be used as a visual cue by an approaching herbivore. Here, we use a spatially-explicit geometric morphometric approach, i.e. taking into account how leaf shape varies both within and between species over distance, to quantify leaf morphology in two species from a natural 
forest population in New Zealand. Geometric morphometrics provide a higher resolution of captured shape information than do the more traditional measurements (Rohlf and Marcus 1993, Klingenberg 2010).

Our focal plant, Alseuosmia pusilla (Alseuosmiaceae), is an understory shrub found in conifer-broadleaf and beech forests of New Zealand. The species has attracted attention because leaf size, shape, and anthocyanin pigmentation make the leaves of individual plants at some locations indistinguishable, at least to the human eye, from those of an unrelated species, Pseudowintera colorata (Winteraceae), with which it is often sympatric (Fig. 1A) (Greenwood and Atkinson 1977, Dawson 1988, Atkinson and Greenwood 1989). The leaves of $A$. pusilla contain only a few anti-herbivory compounds (Cambie and Parnell 1970) and are readily eaten by introduced ungulates (Greenwood and Atkinson 1977, Nugent et al. 2001); in contrast, those of $P$. colorata are rich in polygodial, a sesquiterpene dialdehyde which imparts a pungent taste and is a potent insect anti-feedent (Asakawa et al. 1988). $P$. colorata leaves are also unpalatable to introduced herbivorous mammals (Forsyth et al. 2005), and, it has been suggested, may similarly have been avoided by moa (Greenwood and Atkinson 1977), the extinct flightless birds which are thought to have presented significant browsing pressure on New Zealand's flora over the last 65 million years (Atkinson and Greenwood 1989, Wood et al. 2013). It has been postulated that at locations where the two plant species co-occur, A. pusilla may escape predation by effectively functioning as a Batesian mimic of P. colorata (Dawson 1988, Atkinson and Greenwood 1989). However, this hypothesis lacks any empirical evidence. 
We hypothesise that: (i) leaf shape of $P$. colorata is sufficiently distinct from those of neighbouring plant species such that its morphology might serve to signal its unpalatability; (ii) the leaf shape is shared exclusively by the undefended $A$. pusilla; (iii) variation in $P$. colorata leaf shape across an environmental gradient is matched by variation in foliar morphology of A. pusilla; and (iv) leaf shape similarity is greater the closer the two species are to one another.

\section{Methods}

\section{Plant Material}

Pseudowintera colorata (Raoul) Dandy and Alseuosmia pusilla (Colenso) A. Cunningham leaves were collected from a 4.5km stretch of track (S40 53.30, E175 14.22 to S40 54.46, E175 15.37) through montane forest in the Otaki Forks region of the Tararua Forest Park, New Zealand. The collection area covered the full altitudinal range for the two species at this location $(470-870 \mathrm{~m})$, characterised by a shift from the lower conifer-broadleaf forest to the higher Lophozonia- and Fuscospora-dominated forest. A. pusilla grew along the entire transect; $P$. colorata was most common above $720 \mathrm{~m}$ along the final $1.5 \mathrm{~km}$ of the transect, where it became the prominent understorey tree. Every P. colorata and A. pusilla within $2 \mathrm{~m}$ of one side of the track was sampled if the plants were between $15 \mathrm{~cm}$ and $2 \mathrm{~m}$ tall, and their location recorded using a Garmin 60 GPS (Olathe, USA; accuracy: $\pm 2-10 \mathrm{~m}$ ). The youngest fully expanded leaf was excised from a total of 211 P. colorata and $467 \mathrm{~A}$. pusilla plants. When there were multiple branches, the youngest fully expanded leaf was removed from the highest branch. 
In addition, we collected leaves from seven other tree and shrub species for leaf size and shape were similar to our focal species, and which were located within $1.5 \mathrm{~m}$ of $P$. colorata and $A$. pusilla plants. Between 60 and 130 individuals from each species were sampled; one leaf was collected from each individual from the closest branch facing the nearest $P$. colorata or A. pusilla plant. All leaves were refrigerated within 6 hours of collection.

\section{Leaf Shape Capturing}

Digital images of the adaxial surface of the leaves were captured using a Canon CanoScan 8400F flatbed scanner (Tokyo, Japan) at 600 dpi. Adobe Photoshop 5.0 (San Jose, CA, USA) was used to re-create the original leaf shape by filling in any areas lost to herbivory. If the herbivory damage was too extensive for a confident reconstruction, the original leaf shape was estimated from comparison with that of remaining adjacent lamina. Leaf shape was quantified by LeafAnalyser 2.3.0 (Weight et al. 2008) using the Cartesian coordinates of 70 evenly distributed landmarks distributed around the margin of each leaf. The coordinates were exported into R 2.13.1 (The R Foundation for Statistical Computing, Vienna, Austria) for statistical analysis.

\section{Leaf Colour}

The reflectance spectra of green and red portions of a randomly chosen sub sample of $P$. colorata $($ red $\mathrm{N}=5$, green $\mathrm{N}=8)$, and $A$. pusilla $($ red $\mathrm{N}=4$, green $\mathrm{N}=9)$ leaves were recorded using an Ocean Optics (Dunedin, FL, USA) USB2000 spectrometer and with an HL-2000-CAL light source. Diffuse reflectance was measured relative to that of a white Teflon standard. The fibre optics probe was fixed at $45^{\circ}$ to the leaf's adaxial surface and 
spectra were measured at $0.2 \mathrm{~nm}$ intervals from $450-700 \mathrm{~nm}$ using the Ocean Optics SpectraSuite software.

\section{Statistical Analysis}

Cartesian coordinates were transformed into partial Procrustes coordinates using the software package PAST 2.17c (Hammer et al. 2001) to minimise differences in leaf orientation of the scanned images without scaling for leaf area. To quantify the similarity in overall leaf shape between P. colorata, A. pusilla and the surrounding plant species at the field site, the partial Procrustes coordinate residuals (i.e., tangent space coordinates) sourced from PAST 2.17c were used in a discriminant function analysis (DA) with IBM SPSS Statistics version 20 for Windows (Armonk, NY, USA). Using the full data set of all species as a training set, DA reclassified each individual leaf blindly into a species group based on how variation of leaf shape compared to the leaf shape of all individuals in the set.

Because the sampling site spanned an altitudinal gradient of $400 \mathrm{~m}$, we examined how variation in leaf shape between the two species altered with altitude. A principal component analysis (PCA) was run using the 70 partial Procrustes coordinates, reducing the number for each species into four principle components (PC) that explained the majority of shape variation for each leaf. Linear regressions for each $\mathrm{PC}$ as a function of altitude were compared for each species by ANCOVA.

To quantify spatial variation in leaf shape, we compared the Euclidean distances among $A$. pusilla and $P$. colorata plants on each PC plot with the geographical distances among them. 
To do this, the PC data were exported into R 2.13.1, whereupon the PC score of each $A$. pusilla or P. colorata was compared in turn to the PC scores of all individuals of the opposing species located within a $10 \mathrm{~m}$ radius. The radial distance from the focal plant was progressively increased in $10 \mathrm{~m}$ bands, and the process repeated until every individual of the opposing species across the sampling site had been compared. Using the log-likelihood function we tested the likelihood of how similar each individual's leaf shape was to those of the cohort of surrounding members of the second species at each $10 \mathrm{~m}$ interval as compared with those of the remaining members.

\section{Results}

Leaf Morphology

The leaf laminae of $A$. pusilla ranged from elliptic to cuneate, with an attenuate base and an acute apex, on average $77.3 \pm 34.7 \mathrm{~mm}(95 \%$ C.I.) long and $24.0 \pm 8.3 \mathrm{~mm}$ wide (Fig. 1B). They were sub-membranaceous, glabrous and entire, borne on a petiole up to $10 \mathrm{~mm}$ long. $P$. colorata leaves were also typically elliptic but ranged to ovate; their laminae were coriaceous, glabrous, and entire or undulate, had a cuneate base and an acute to obtuse apex, and were generally larger than $A$. pusilla at $88.5 \pm 36.6 \mathrm{~mm}$ long and $30.2 \pm 12.1 \mathrm{~mm}$ wide, with a $\leq 10 \mathrm{~mm}$ petiole (Fig. 1C). Across the population the two species overlapped in leaf dimensions; $62 \%$ of $A$. pusilla and $61 \%$ of $P$. colorata leaves were within 1 standard deviation (S.D.) of the other's mean lamina length, and 51\% of $A$. pusilla and $29 \%$ of $P$. colorata leaves were within 1 S.D. of the other's mean leaf width. The two species shared similar reflectance spectra for the green as well as for the red portions of the leaf's adaxial surface (Figs. 2A, 2B), indicating that there was negligible difference in lamina colour. 
Shape Analysis

The first four principle components of the PCA analysis accounted for $98.0 \%$ of the total leaf shape variation. Most (89.6\%) of this was attributable to variation in leaf size and to sizeassociated shape differences represented by PC1 (Fig. 3A), with leaves of $A$. pusilla being generally smaller than those of $P$. colorata. In the remaining three PCs, $P$. colorata exhibited the wider variation in leaf shape, as evidenced by a greater spread in S.D. as compared with A. pusilla. PC2 accounted for $4.1 \%$ of the total variance in shape; it represented the morphological progression from an asymmetric elliptic for which lamina area was greater at the left- than at the right-hand side of the midrib as viewed from the leaf base on the adaxial surface (abbreviated hereafter as 'left-biased'), through to an asymmetric 'right-biased' cuneate lamina (Fig. 3B). PC3 accounted for 3.4\% of the variance and represented the opposite range to PC2, lamina shape varying from right-biased elliptic to left-biased cuneate (Fig. 3C). PC4 accounted for $1.0 \%$ of the variance, representing shapes from narrow linear to an elliptic (Fig. 3D).

\section{Shape Discrimination}

The leaf shapes of $P$. colorata and A. pusilla were morphometrically distinct from those of all seven other species growing in their vicinity; $97.3 \%$ of $P$. colorata and A. pusilla leaves (grouped together) were correctly identified by discriminant analysis. When the analysis was restricted to $P$. colorata and $A$. pusilla only, discriminant analysis incorrectly classified $7.1 \%$ of $A$. pusilla, of which most (5.4\%) were classified as P. colorata. For P. colorata, $29.4 \%$ were misidentified as A. pusilla; none was misidentified as any other species (Table 1). Thus, $34.8 \%$ of $A$. pusilla and P. colorata were statistically indistinguishable from each other. 
P. colorata exhibited a more even spread of individuals within \pm 3 S.D. from the mean leaf shape than $\operatorname{did}$ A. pusilla, especially in the characteristics represented by PC2 to PC4 (Figs. 3A-D). A. pusilla had a narrower range of shapes characterised by a greater proportion of individuals approaching its mean leaf shape; thus, it was easier for the discriminant analysis to categorise the species correctly, explaining why a greater proportion of $P$. colorata was mistaken as $A$. pusilla rather than the other way round. $A$. pusilla individuals that were found beyond \pm 3 S.D. from their mean leaf shape were closer to the mean shape of $P$. colorata than to their own mean shape (Table 1).

\section{Altitudinal variation in leaf shape}

Leaf size and shape represented by PC1 increased similarly in both species at higher altitudes (species identity: $\mathrm{r}^{2}=0.21, \mathrm{P}<0.001$; slopes are parallel: d.f $=1, \mathrm{~F}=0.28, \mathrm{P}=0.59$; Fig. 4A). Leaves of P. colorata were constantly larger across the altitudinal gradient (intercepts differ: $d . f=1, F=170, P<0.001)$. However, some features of leaf shape varied with altitude differently between the species (all interactions between species and altitude in PC2, PC3, PC4 were statistically significant; $\mathrm{P}<0.05)$. In A. pusilla leaf shape shifted from left-biased elliptic to right-biased cuneate, whilst $P$. colorata shifted slightly in the opposite direction (PC2; Fig. 4B). For the attributes associated with PC3, the left-biased cuneate laminae of $A$. pusilla became less abundant at higher altitudes, replaced by right-biased elliptic leaves; there was no effect in P. colorata (Fig. 4C). Finally, the narrow linear laminae of A. pusilla (PC4) were replaced by more elliptic laminae, while there was no effect in P. colorata (Fig. 4D).

Shape comparison among neighbours 
The probability that leaves of $A$. pusilla would be similar in shape to those of $P$. colorata was greater the closer the two species were to one another (Figs. 5A-D). This probability fell rapidly at separation distances greater than about $200 \mathrm{~m}$, irrespective of which criterion was used to describe shape. Similarity in leaf size and shape (represented by PC1) declined the most with increasing separation distance (Fig. 5A), followed by characters represented by PC2 (Fig. 5B) and then PC3 (Fig. 5C). Leaves that varied from narrow linear to elliptic (PC4 characters) were the least likely to change over distance (Fig. 5D). Patterns of similarity between $P$. colorata individuals and the surrounding $A$. pusilla did not change along the transect (see Figs. 6A-D).

\section{Discussion}

There are five key findings from this study of spatial variation in leaf shape. (i) The chemically defended $P$. colorata is morphologically distinct from all surrounding heterospecifics except for A. pusilla (Table 1). (ii) The range of leaf shapes of P. colorata overlaps significantly with that of $A$. pusilla, meaning that $35 \%$ of the leaves of the two species cannot be statistically distinguished from one another (Table 1). (iii) P. colorata and A. pusilla share similar lamina colours (Figs. 2A, 2B). (iv) Leaf shape in the two species varies similarly across an altitudinal gradient (Fig. 4A-D). (v) Leaves of $A$. pusilla are more likely to resemble those of $P$. colorata the closer the two species are to one another (Fig. 5AD). These results add weight to the hypothesis that $A$. pusilla could be a Batesian mimic of $P$. colorata.

Batesian mimicry requires that distinguishable traits shared by model and mimic are identifiable by the predator and associated with unpalatability; the more conspicuous the 
signal, the more readily is this association learned (Cott 1940, Harvey 1983). For leaf shape to be effective as a visual deterrent, it would therefore need to be sufficiently distinct from those of surrounding species. Previous studies of putative Batesian mimics did not always address the question that the shared traits are exclusive to the putative model and mimic. Certain Australian mistletoes, for example, are remarkably similar in leaf colour and shape to those of their hosts (Barlow and Wiens 1977, Ehleringer et al. 1986), yet some of these similarities are also shared with other species in the surrounding plant community (Blick et al. 2012) and so it is likely that herbivores would use different features to discriminate between them (Canyon and Hill 1997). Like the mistletoes, the leaves of our putative model and mimic are very similar in shape and colouration; $35 \%$ of the leaves were statistically indistinguishable from one another. However, in contrast to the mistletoes, leaf shapes in our focal species are substantially different from those of all other sympatric trees and shrubs; discriminant analysis correctly classified $97 \%$ of $A$. pusilla and P. colorata when they were grouped together and compared against the surrounding species. Thus, there is a real possibility that leaf shape per se might be used as a visual deterrent in these species.

Leaf shape often changes along environmental gradients (McDonald et al. 2003). Thus, if mimicry is to be effective, both the model and mimic would need to respond similarly to any environmental factor that affects leaf shape. Along the altitudinal gradient spanned by our transect, changes in leaf size, and in leaf shape related to variation in leaf size, were similar for P. colorata and A. pusilla (Fig. 4A); these were PC1 features, accounting for $90 \%$ of the total shape variation shared between the two species (Fig. 3A). Moreover, the leaves of $A$. pusilla were morphologically most similar to those of neighbouring P. colorata within a radius of around $200 \mathrm{~m}$, with a sharp decline in leaf similarity among plants that were further 
apart (Figs. 5A-D). We do not know the degree to which genetic and environmental factors control leaf shape in these species, but it is evident that the two respond very similarly.

A foraging herbivore would most likely encounter potential food sources in succession rather than simultaneously, and would therefore rely on memory to associate leaf morphology with unpalatability. The accuracy of discriminating between successively viewed objects decreases rapidly due to inefficiencies in coding and retrieving of memories, as shown both in humans (Uchikawa and Ikeda 1981) and honeybees (Dyer and Neumeyer 2005). Thus, effective mimicry does not require that the mimics be exact replicas of their models; a plant would need only to resemble its protected neighbours with sufficient accuracy to account for the level of degraded memory. Rather than a general similarity in leaf morphology, the similarity shared between $A$. pusilla and its immediate $P$. colorata neighbours, which is maintained across the shared growing range, would further reduce a foraging herbivore's ability to discriminate between them.

We do not know which of the potential herbivores may have been important in driving the evolution of leaf morphology in A. pusilla. The terrestrial fauna was historically dominated by moa, which were generalist herbivores consuming a wide variety of plants (Wood et al. 2008,2012 ), but there is no evidence to suggest that they were the main selective pressure in this system. Little, too, is known about the insect herbivores of $A$. pusilla. Forest populations of $A$. pusilla often show evidence of damage by Lepidopteran larvae, but it is not known whether these and/or other herbivorous invertebrates attack or are deterred by P. colorata. Insects have poor spatial acuity compared with larger vertebrates (Giurfa et al. 1996), but once close enough to a plant they may similarly resolve small objects to recognise patterns 
and shapes (Giurfa and Menzel 1997). Thus, leaves might well have been used by not only moa, but also insect herbivores for identification purposes.

Unequivocal proof of mimicry requires evidence that: (i) both the mimic and a known model are attacked by the same herbivore; (ii) the herbivore is unable to distinguish between them; and (iii) this confusion increases the fitness of the mimic. To date, no study has satisfied these three criteria in plants (Schaefer and Ruxton 2009, 2011). However, our study provides strong evidence that leaf shape is precisely matched between an undefended plant species and a chemically-defended unrelated species across a shared growing range, and therefore represents an important first step at establishing Batesian mimicry between $A$. pusilla and the putative model, P. colorata. We highlight how a spatially-explicit morphometric analysis provides a powerful tool to study visual Batesian mimicry in plants.

\section{Acknowledgements}

We thank Mikey Willcox for field assistance, and Timo Brockmeyer for technical help. This research was approved under Part IIIB of the Conservation Act 1987 and Section 49 of the Reserves Act 1977 with the New Zealand Department of Conservation permit number WE/25115/FLO.

\section{References}

Anten, N.P.R., Alcalá-Herrera, R., Schieving, F., and Onoda, Y. 2010. Wind and mechanical stimuli differentially affect leaf traits in Plantago major. New Phytol. 188(2): 554-564. doi:10.1111/j.1469-8137.2010.03379.x. 
Asakawa, Y., Dawson, G.W., Griffiths, D.C., Lallemand, J.Y., Ley, S.V., Mori, K., Mudd, A., Pezechk-Leclaire, M., Pickett, J.A., Watanabe, H., Woodcock, C.M., and Zhong-Ning, Z. 1988. Activity of drimane antifeedants and related compounds against aphids, and comparative biological effects and chemical reactivity of $(-)$ and $(+)$ polygodial. J. Chem. Ecol. 14(10): 1845-55. doi:10.1007/BF01013481.

Atkinson, I.A.E., and Greenwood, R.M. 1989. Relationships between moas and plants. N. Z. J. Ecol. 12(2): 67-96. Available from http://www.jstor.org/stable/24053251 [accessed 15 November 2011].

Barlow, B.A., and Wiens, D. 1977. Host-parasite resemblance in Australian mistletoes: the case for cryptic mimicry. Evolution 31(1): 69-84. doi:10.2307/2407546.

Blick, R.A.J., Burns, K.C., and Moles, A.T. 2012. Predicting network topology of mistletoehost interactions: do mistletoes really mimic their hosts? Oikos 121(5): 761-771. doi:10.1111/j.1600-0706.2011.19854.x.

Brown, V.K., and Lawton, J.H. 1991. Herbivory and the Evolution of Leaf Size and Shape. Philos. Trans. R. Soc. Biol. Sci. 333(1267): 265-272. doi:10.1098/rstb.1991.0076.

Cambie, R.C., and Parnell, J.C. 1970. New Zealand phytochemical survey. 8. Constituents of some New Zealand plants. New Zeal. J. Sci. 13(1): 108-116.

Campitelli, B.E., Simonsen, A.K., Rico Wolf, A., Manson, J.S., and Stinchcombe, J.R. 2008. Leaf shape variation and herbivore consumption and performance: a case study with Ipomoea hederacea and three generalists. Arthropod. Plant. Interact. 2(1): 9-19. doi:10.1007/s11829007-9028-X. 
Canyon, D.V., and Hill, G.J. 1997. Mistletoe host-resemblance: A study of herbivory, nitrogen and moisture in two Australian mistletoes and their host trees. Austral Ecol. 22(4): 395-403. doi:10.1111/j.1442-9993.1997.tb00689.x.

Cott, H.B. 1940. Adaptive Coloration in Animals. Methuen, London.

Cunningham, S.A., Summerhayes, B., and Westoby, M. 1999. Evolutionary divergences in leaf structure and chemistry, comparing rainfall and soil nutrient gradients. Ecol. Monogr. 69(4): 569-588. doi:10.1890/0012-9615(1999)069[0569:EDILSA]2.0.CO;2.

Dawson, J.W. 1988. Forest Vines to Snow Tussocks: The story of New Zealand plants. Victoria University Press, Wellington.

Dyer, A.G., and Neumeyer, C. 2005. Simultaneous and successive colour discrimination in the honeybee (Apis mellifera). J. Comp. Physiol. A. Neuroethol. Sens. Neural. Behav. Physiol. 191(6): 547-557. doi:10.1007/s00359-005-0622-z.

Ehleringer, J.R., Ullmann, I., Lange, O.L., Farquhar, G.D., Cowan, I.R., Schulze, E.D., and Ziegler, H. 1986. Mistletoes: a hypothesis concerning morphological and chemical avoidance of herbivory. Oecologia 70(2): 234-237. doi:10.1007/BF00379245.

Forsyth, D.M., Richardson, S.J., and Menchenton, K. 2005. Foliar fibre predicts diet selection by invasive Red Deer Cervus elaphus scoticus in a temperate New Zealand forest. Funct. Ecol. 19(3): 495-504. doi:10.1111/j.1365-2435.2005.00991.x.

Gianoli, E., and Carrasco-Urra, F. 2014. Leaf Mimicry in a Climbing Plant Protects against Herbivory. Curr. Biol. 24(9): 984-987. Elsevier Ltd. doi:10.1016/j.cub.2014.03.010.

Giurfa, M., and Menzel, R. 1997. Insect visual perception: complex abilities of simple nervous systems. Curr. Opin. Neurobiol. 7(4): 505-13. doi:10.1016/S0959-4388(97)80030X. 
Giurfa, M., Vorobyev, M., Kevan, P., and Menzel, R. 1996. Detection of coloured stimuli by honeybees: minimum visual angles and receptor specific contrasts. J. Comp. Physiol. A 178(5): 699-709. doi:10.1007/BF00227381.

Greenwood, R.M., and Atkinson, I.A.E. 1977. Evolution of divaricating plants in New Zealand in relation to moa browsing. Proc. New Zeal. Ecol. Soc. 24: 21-33. Available from http://www.jstor.org/stable/24052033 [accessed 11 February 2013].

Gurevitch, J., and Schuepp, P.H. 1990. Boundary layer properties of highly dissected leaves: an investigation using an electrochemical fluid tunnel. Plant. Cell Environ. 13(8): 783-792. doi:10.1111/j.1365-3040.1990.tb01094.x.

Hammer, Ø., Harper, D.A.T., and Ryan, P.D. 2001. PAST: Paleontological Statistics Software Package for Education and Data Analysis. Palaeontol. Electron. 4(1): 1-9. doi:10.1016/j.bcp.2008.05.025.

Harvey, P.H. 1983. Why some insects look pretty nasty. New Sci. 97(1339): 26-27.

Hegazy, A.K., and El Amry, M.I. 1998. Leaf temperature of desert sand dune plants: Perspectives on the adaptability of leaf morphology. Afr. J. Ecol. 36(1): 34-43. doi:10.1046/j.1365-2028.1998.109- 89109.x.

Horn, H.S. 1971. The adaptive geometry of trees. Princeton University Press, Princeton.

Hovenden, M.J., and Vander Schoor, J.K. 2006. The response of leaf morphology to irradiance depends on altitude of origin in Nothofagus cunninghamii. New Phytol. 169(2): 291-297. doi:10.1111/j.1469-8137.2005.01585.x.

Klingenberg, C.P. 2010. Evolution and development of shape: integrating quantitative approaches. Nat. Rev. Genet. 11(9): 623-35. Nature Publishing Group. doi:10.1038/nrg2829. 
Leigh, A., Zwieniecki, M.A., Rockwell, F.E., Boyce, C.K., Nicotra, A.B., and Holbrook, N.M. 2011. Structural and hydraulic correlates of heterophylly in Ginkgo biloba. New Phytol. 189(2): 459-470. doi:10.1111/j.1469-8137.2010.03476.x.

Mackay, D.A., and Jones, R.E. 1989. Leaf shape and the host-finding behaviour of two ovipositing monophagous butterfly species. Ecol. Entomol. 14(4): 423-431.

doi:10.1111/j.1365-2311.1989.tb00944.x.

McDonald, P.G., Fonseca, C.R., Overton, J.M., and Westoby, M. 2003. Leaf-size divergence along rainfall and soil-nutrient gradients: is the method of size reduction common among clades? Funct. Ecol. 17(1): 50-57. doi:10.1046/j.1365-2435.2003.00698.x.

Nicotra, A.B., Leigh, A., Boyce, C.K., Jones, C.S., Niklas, K.J., Royer, D.L., and Tsukaya, H. 2011. The evolution and functional significance of leaf shape in the angiosperms. Funct. Plant Biol. 38(7): 535-552. CSIRO. doi:10.1071/FP11057.

Niemelä, P., Tuomi, J. 1987. Does the leaf morphology of some plants mimic caterpillar damage? Oikos 50(2): 256-257. doi:10.2307/3566009.

Nugent, G., Fraser, K.W., Asher, G.W., and Tustin, K.G. 2001. Advances in New Zealand mammalogy 1990-2000: Deer. J. R. Soc. New Zeal. 31(1): 263-298.

doi:10.1080/03014223.2001.9517654.

Rausher, M. 1978. Search image for leaf shape in a butterfly. Science 200(4345): 1071-1073. doi:10.1126/science.200.4345.1071.

Rivero-Lynch, A.P., Brown, V.K., and Lawton, J.H. 1996. The impact of leaf shape on the feeding preference of insect herbivores: experimental and field studies with Capsella and Phyllotreta. Philos. Trans. R. Soc. B Biol. Sci. 351(1348): 1671-1677. doi:10.1098/rstb.1996.0149. 
Rohlf, F.J., and Marcus, L.F. 1993. A revolution in morphometrics. Trends Ecol. Evol. 8(4): 129-132. doi:10.1016/0169-5347(93)90024-J.

Roth-Nebelsick, A. 2001. Computer-based analysis of steady-state and transient heat transfer of small-size leaves by free mixed convection. Plant, Cell Environ. 24(6): 631-640. doi:10.1046/j.1365-3040.2001.00712.x.

Royer, D.L., Meyerson, L.A., Robertson, K.M., and Adams, J.M. 2009. Phenotypic plasticity of leaf shape along a temperature gradient in Acer rubrum. PLoS One 4(10): e7653. doi:10.1371/journal.pone.0007653.

Schaefer, H.M., and Ruxton, G.D. 2009. Deception in plants: mimicry or perceptual exploitation? Trends Ecol. Evol. 24(12): 676-685. doi:10.1016/j.tree.2009.06.006.

Schaefer, H.M., and Ruxton, G.D. 2011. Plant-animal communication. Oxford University Press, Oxford.

Shimshi, D. 1979. Two ecotypes of Iris atrofusca Bak. and their relationship to manmodified habitats. Isr. J. Bot. 28(2): 80-86. doi:10.1080/0021213X.1979.10676859.

Sinclair, C., and Hoffmann, A.A. 2003. Monitoring salt stress in grapevines: Are measures of plant trait variability useful? J. Appl. Ecol. 40(5): 928-937. doi:10.1046/j.13652664.2003.00843.x.

Tsukaya, H. 2005. Leaf shape: genetic controls and environmental factors. Int. J. Dev. Biol. 49(5-6): 547-555. doi:10.1387/ijdb.041921ht.

Uchikawa, K., and Ikeda, M. 1981. Temporal deterioration of wavelength discrimination with successive comparison method. Vision Res. 21(4): 591-595. doi:10.1016/00426989(81)90106-1. 
Weight, C., Parnham, D., and Waites, R. 2008. LeafAnalyser: a computational method for rapid and large-scale analyses of leaf shape variation. Plant J. 53(3): 578-586.

doi:10.1111/j.1365-313X.2007.03330.x.

Wheeler, K.G.R. 2004. A natural history of nettles. Trafford, Victoria.

Wood, J.R., Rawlence, N.J., Rogers, G.M., Austin, J.J., Worthy, T.H., and Cooper, A. 2008. Coprolite deposits reveal the diet and ecology of the extinct New Zealand megaherbivore moa (Aves, Dinornithiformes). Quat. Sci. Rev. 27(27-28): 2593-2602. Elsevier Ltd. doi:10.1016/j.quascirev.2008.09.019.

Wood, J.R., Wilmshurst, J.M., Richardson, S.J., Rawlence, N.J., Wagstaff, S.J., Worthy, T.H., and Cooper, A. 2013. Resolving lost herbivore community structure using coprolites of four sympatric moa species (Aves: Dinornithiformes). Proc. Natl. Acad. Sci. U. S. A. 110(42): 16910-16915. doi:10.1073/pnas.1307700110.

Wood, J.R., Wilmshurst, J.M., Wagstaff, S.J., Worthy, T.H., Rawlence, N.J., and Cooper, A. 2012. High-resolution coproecology: using coprolites to reconstruct the habits and habitats of New Zealand's extinct upland moa (Megalapteryx didinus). PLoS One 7(6): e40025. doi:10.1371/journal.pone.0040025. 
Table 1. Probability of correct identification of species by cross validated discriminant analysis using the leaf margin landmarks.

\begin{tabular}{lcccccccccc}
\hline \multirow{2}{*}{$\begin{array}{l}\text { Original species group } \\
\text { membership }\end{array}$} & \multicolumn{8}{c}{ Predicted species group membership based on leaf } \\
\cline { 2 - 11 } & L.m & C.c & C.f & C.g & G.l & M.s & P & A.p & P.c \\
\hline Lophozonia menziesii (L.m) & 76.9 & 19.2 & 0.0 & 0.0 & 0.0 & 0.0 & 0.0 & 3.8 & 0.0 \\
Coprosma colensoi $($ C.c $)$ & 0.0 & 96.3 & 0.0 & 3.1 & 0.0 & 0.0 & 0.0 & 0.5 & 0.0 \\
Coprosma foetidissima $($ C.f) & 0.0 & 0.0 & 80.0 & 6.7 & 0.0 & 0.0 & 0.0 & 10.0 & 3.3 \\
Coprosma grandifolia $($ C.g) & 0.0 & 9.6 & 1.4 & 86.3 & 0.0 & 0.0 & 0.0 & 0.0 & 2.7 \\
Griselinia littoralis $($ G.l) & 0.0 & 0.0 & 0.0 & 0.0 & 89.5 & 5.3 & 0.0 & 5.3 & 0.0 \\
Myrsine salicina $(M . s)$ & 0.0 & 0.0 & 0.0 & 0.0 & 0.0 & 100.0 & 0.0 & 0.0 & 0.0 \\
Prumnopitys spp. $(P)$ & 1.4 & 1.4 & 0.0 & 0.0 & 0.0 & 0.0 & 94.4 & 2.8 & 0.0 \\
Alseuosmia pusilla $($ A.p $)$ & 0.0 & 1.3 & 0.0 & 0.2 & 0.0 & 0.2 & 0.0 & 92.9 & 5.4 \\
Pseudowintera colorata $(P . c)$ & 0.0 & 0.0 & 0.0 & 0.0 & 0.0 & 0.0 & 0.0 & 29.4 & 70.6
\end{tabular}


Fig. 1. Leaf morphology of Pseudowintera colorata and Alseuosmia pusilla. (A) P. colorata (P.c) and A. pusilla (A.p) seedlings growing together under forest canopy (top), and in the open due to tree fall (bottom). (B) Selected examples to show the range of A. pusilla, and (C) P. colorata leaves across the altitudinal gradient. Scale bars: $20 \mathrm{~mm}$.

Fig. 2. Reflectance spectra of leaves. Proportions of reflected light from (A) green, and (B) red portions of Pseudowintera colorata (dashed grey line) and Alseuosmia pusilla (solid black line) lamina. Data are means \pm standard error.

Fig. 3. Principal components analysis (PCA) of leaf shape variation in Pseudowintera colorata and Alseuosmia pusilla. PCA reduced $98.1 \%$ of leaf shape variation between the two species into four principal components (PC1-4). For each PC, proportionate frequencies of $P$. colorata (grey bars) and A. pusilla (black bars) leaves are given for up to 3 standard deviations (S.D.) of the mean leaf shape (0). Leaf silhouettes show typical shapes, proportionately scaled, represented by each 1 S.D. on each PC. (A) PC1, accounted for $89.6 \%$ of total leaf shape variation; (B) PC2, 4.1\%; (C) PC3, 3.4\%; (D) PC4, 1\%.

Fig. 4. Leaf shape of Alseuosmia pusilla and Pseudowintera colorata in relation to altitude. Leaf shape represented by (A) PC1, (B) PC2, (C) PC3, and (D) PC4, as illustrated in Fig. 3. A. pusilla (crosses) and P. colorata (circles). Each point represents one leaf from an individual plant. The y-axes extend \pm 5 S.D. along each PC from the mean leaf shape, which is represented by 0 . Linear regressions show altitudinal trends in leaf shape variation explained by each PC for A. pusilla (black line) and P. colorata (grey line). Leaf silhouettes 
are proportionately scaled and show typical shapes represented by \pm 3 S.D. and the mean leaf shape (0).

Fig. 5. Comparison of individual Alseuosmia pusilla principal component (PC) values to the neighbouring Pseudowintera colorata population. Log-likelihood scores for similarity in leaf shape represented by (A) PC1, (B) PC2, (C) PC3, and (D) PC4, comparing A. pusilla individuals to the surrounding $P$. colorata over distance. Decreases in log-likelihood scores indicate reduced similarities in leaf shape represented by the corresponding PC.

Fig. 6. Comparison of individual Pseudowintera colorata principal component (PC) values to the neighbouring Alseuosmia pusilla population. Log-likelihood scores for similarity in leaf shape represented by (A) PC1, (B) PC2, (C) PC3, and (D) PC4, comparing P. colorata individuals to the surrounding A. pusilla over distance. Decreases in log-likelihood scores indicate reduced similarities in leaf shape represented by the corresponding PC. 

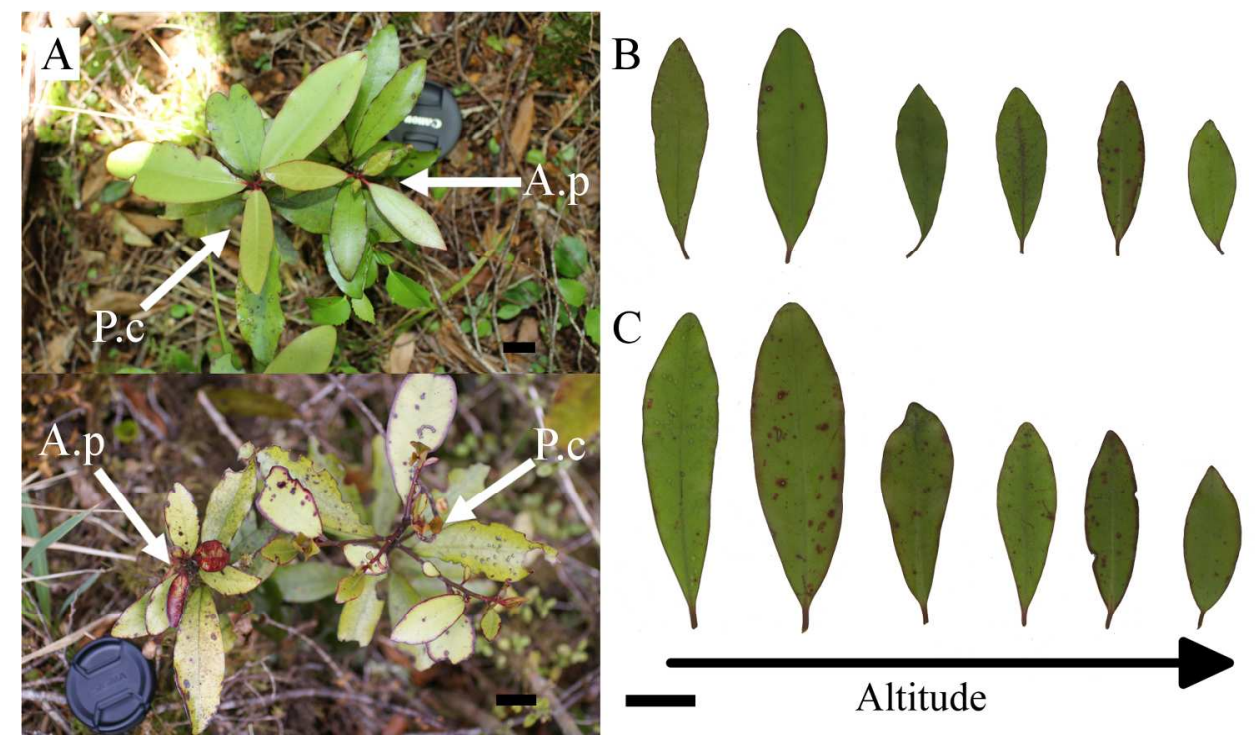

Fig. 1. Leaf morphology of Pseudowintera colorata and Alseuosmia pusilla. (A) P. colorata (P.C) and A. pusilla (A.p) seedlings growing together under forest canopy (top), and in the open due to tree fall (bottom).

(B) Selected examples to show the range of $A$. pusilla, and (C) $P$. colorata leaves across the altitudinal gradient. Scale bars: $20 \mathrm{~mm}$. (To view the figure in colour, the reader is referred to the web version of this article).

$189 \times 105 \mathrm{~mm}(300 \times 300$ DPI $)$ 

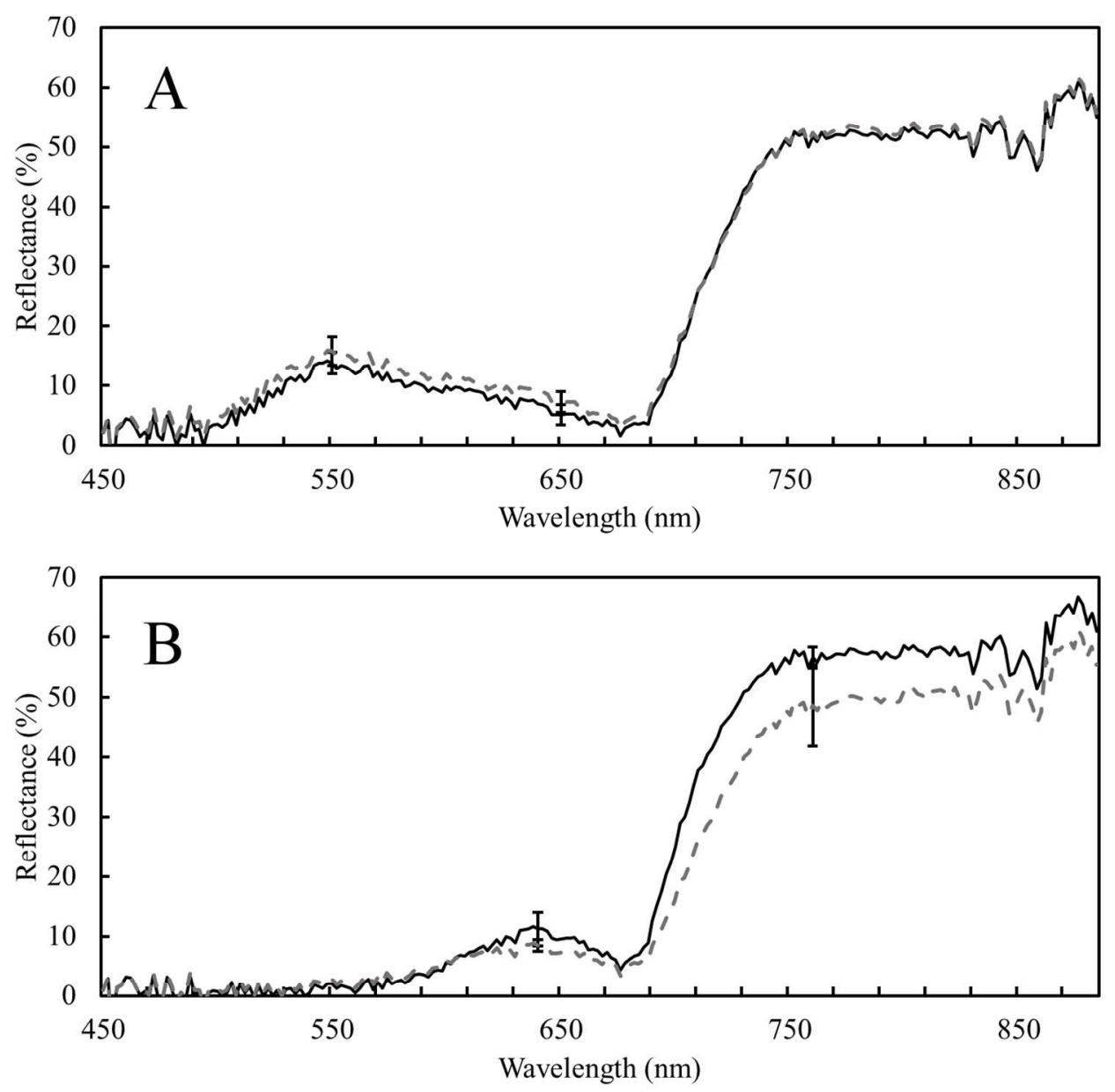

Fig. 2. Reflectance spectra of leaves. Proportions of reflected light from (A) green, and (B) red portions of Pseudowintera colorata (dashed grey line) and Alseuosmia pusilla (solid black line) lamina. Data are means \pm standard error. $124 \times 119 \mathrm{~mm}(300 \times 300 \mathrm{DPI})$ 

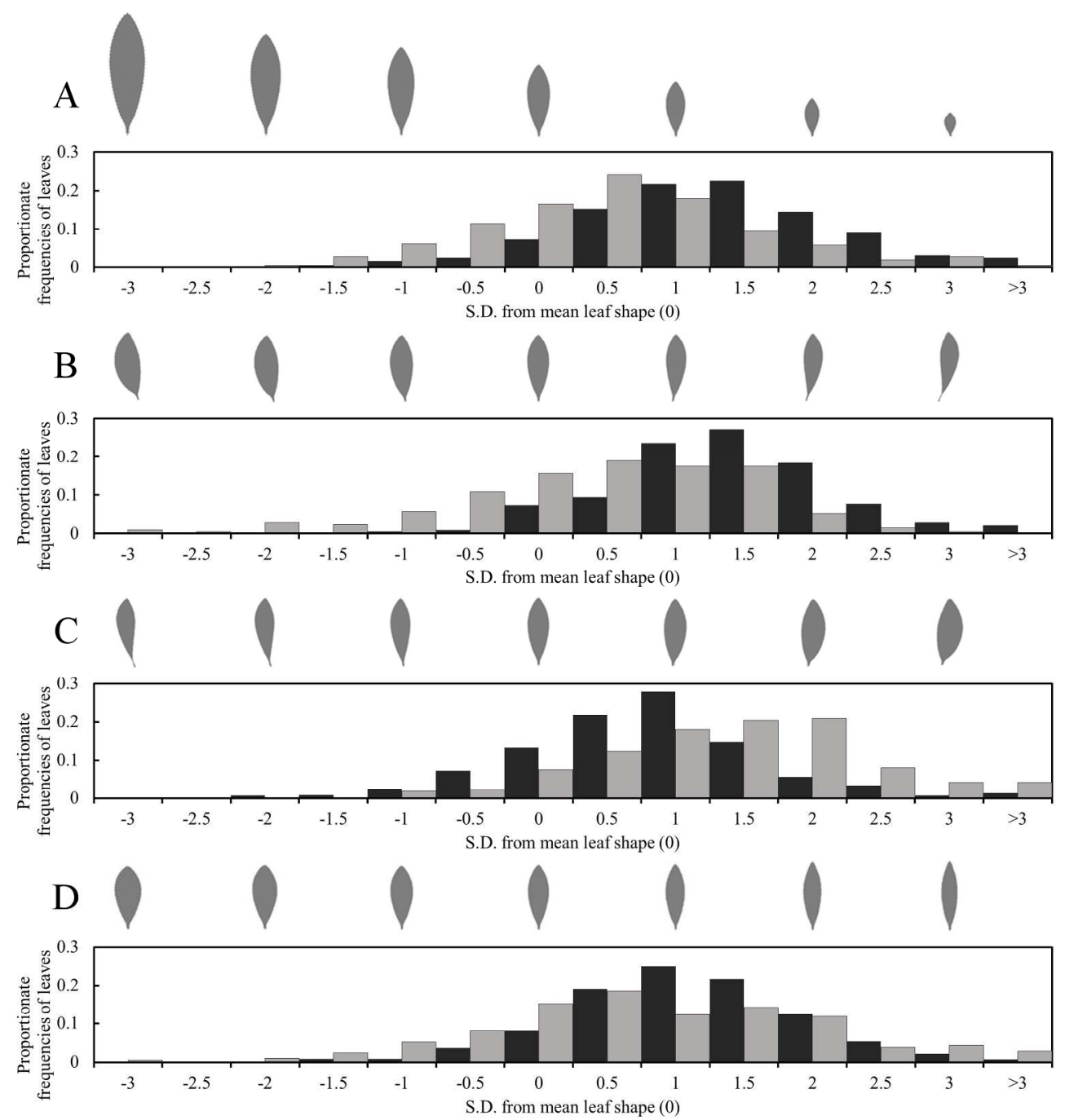

Fig. 3. Principal components analysis (PCA) of leaf shape variation in Pseudowintera colorata and Alseuosmia pusilla. PCA reduced $98.1 \%$ of leaf shape variation between the two species into four principal components (PC1-4). For each PC, proportionate frequencies of $P$. colorata (grey bars) and $A$. pusilla (black bars) leaves are given for up to 3 standard deviations (S.D.) of the mean leaf shape (0). Leaf silhouettes show typical shapes, proportionately scaled, represented by each 1 S.D. on each PC. (A) PC1, accounted for $89.6 \%$ of total leaf shape variation; (B) PC2, 4.1\%; (C) PC3, 3.4\%; (D) PC4, $1 \%$. $189 \times 200 \mathrm{~mm}(300 \times 300 \mathrm{DPI})$ 

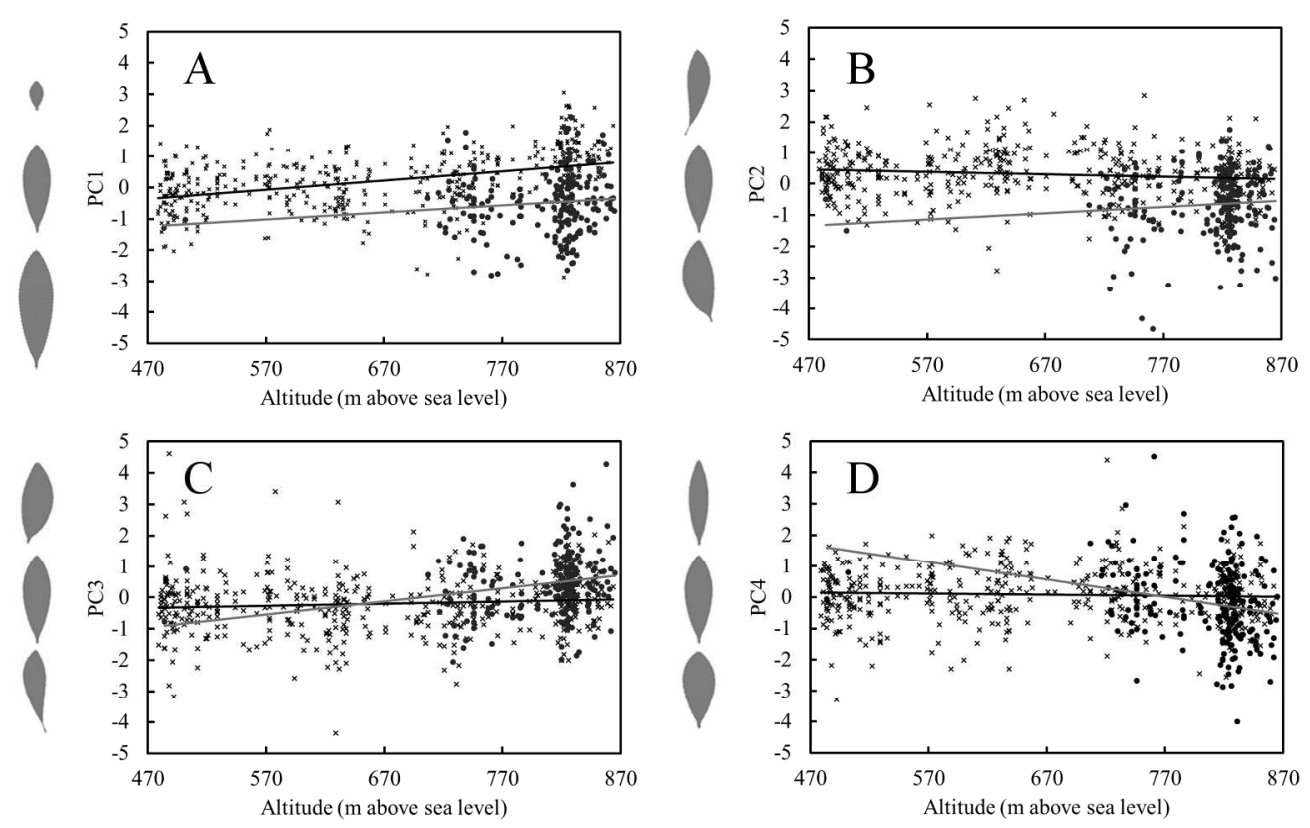

Fig. 4. Leaf shape of Alseuosmia pusilla and Pseudowintera colorata in relation to altitude. Leaf shape represented by (A) PC1, (B) PC2, (C) PC3, and (D) PC4, as illustrated in Fig. 3. A. pusilla (crosses) and $P$. colorata (circles). Each point represents one leaf from an individual plant. The $y$-axes extend \pm 5 S.D. along each PC from the mean leaf shape, which is represented by 0 . Linear regressions show altitudinal trends in leaf shape variation explained by each PC for $A$. pusilla (black line) and $P$. colorata (grey line). Leaf silhouettes are proportionately scaled and show typical shapes represented by \pm 3 S.D. and the mean leaf shape (0).

$189 \times 119 \mathrm{~mm}(300 \times 300$ DPI $)$ 

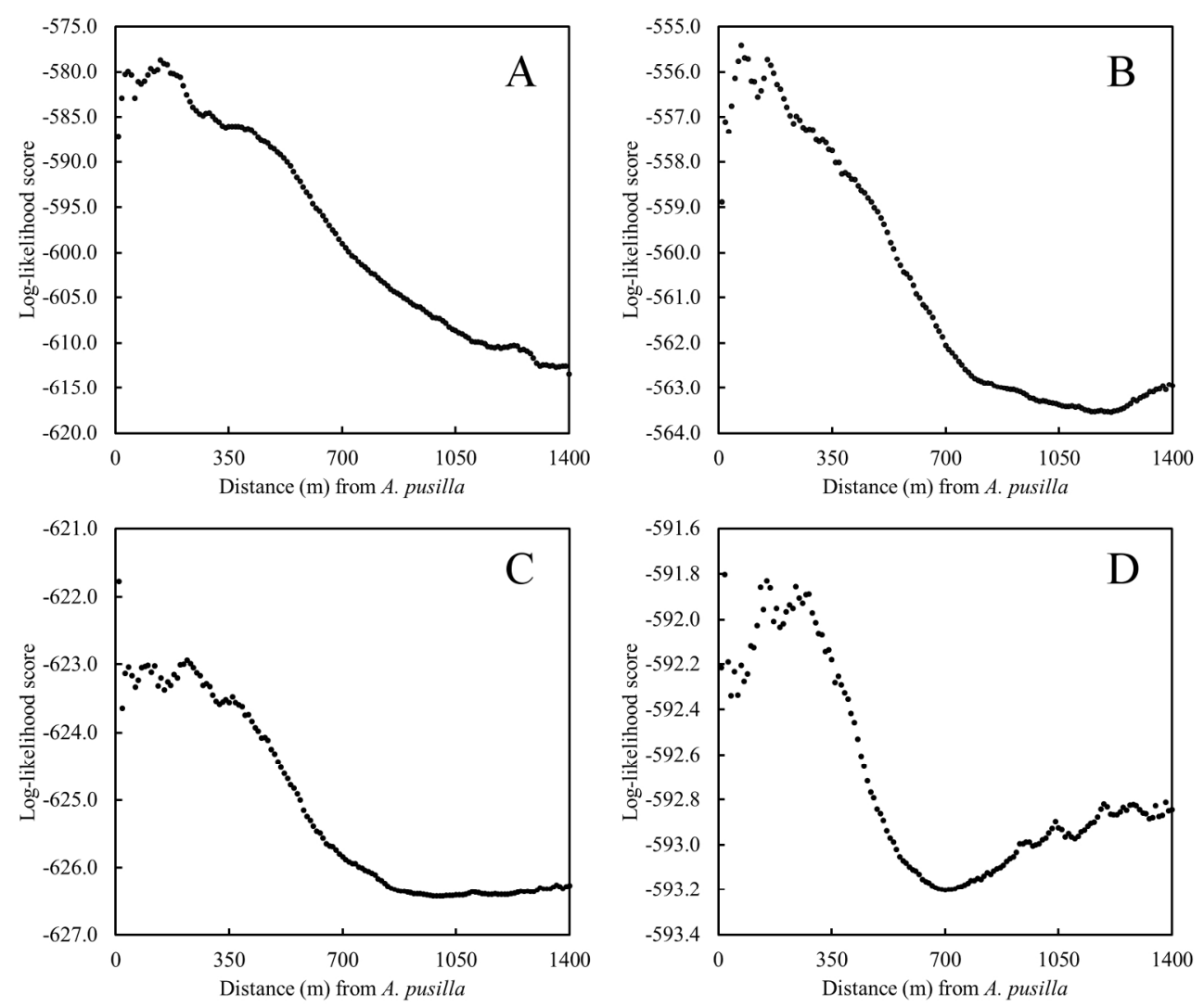

Fig 5. Comparison of individual Alseuosmia pusilla principal component (PC) values to the neighbouring Pseudowintera colorata population. Log-likelihood scores for similarity in leaf shape represented by (A) PC1, (B) PC2, (C) PC3, and (D) PC4, comparing A. pusilla individuals to the surrounding P. colorata over distance.

Decreases in log-likelihood scores indicate reduced similarities in leaf shape represented by the corresponding PC.

$180 \times 150 \mathrm{~mm}(300 \times 300 \mathrm{DPI})$ 

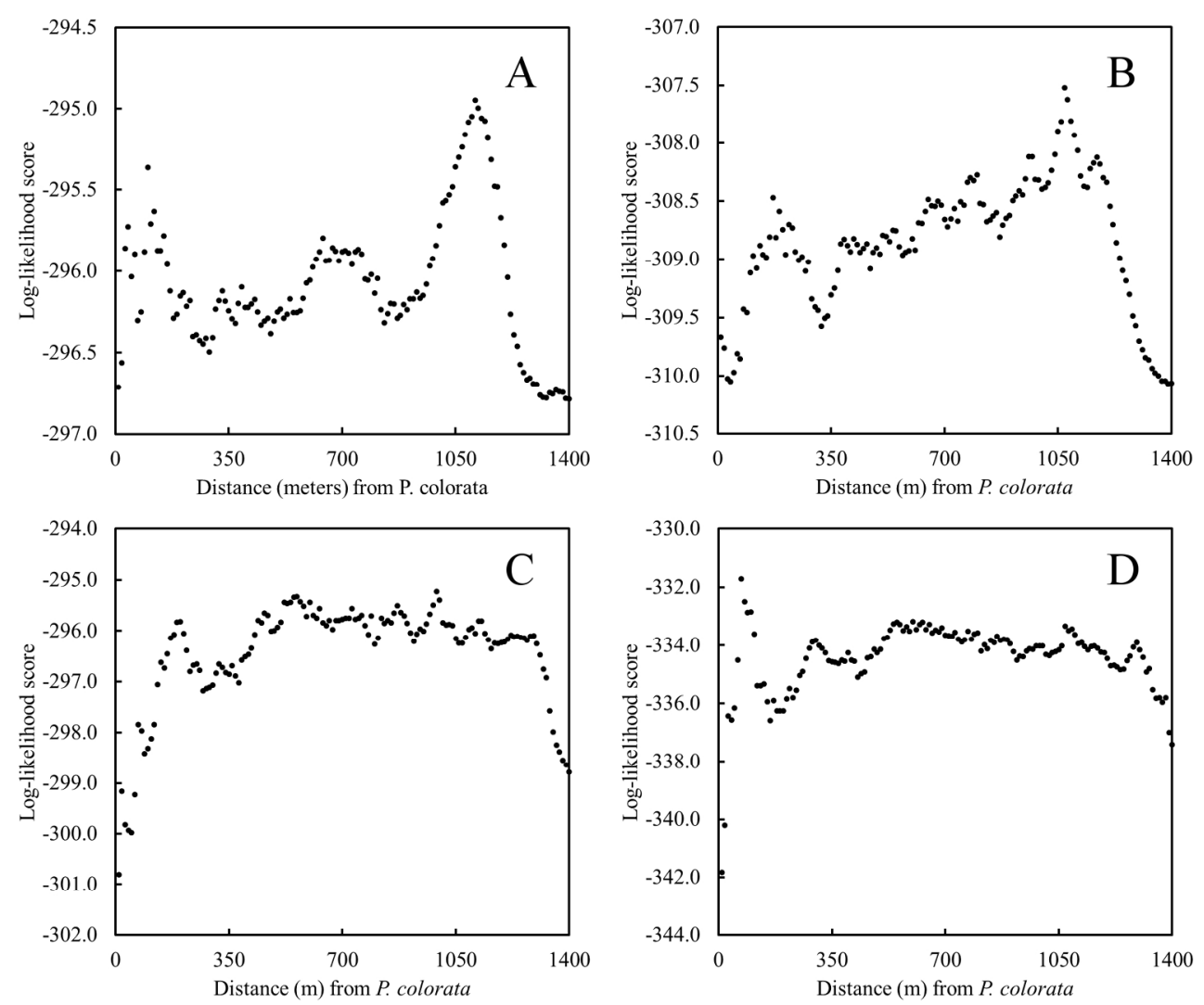

Fig. 6. Comparison of individual Pseudowintera colorata principal component (PC) values to the neighbouring Alseuosmia pusilla population. Log-likelihood scores for similarity in leaf shape represented by (A) PC1, (B) PC2, (C) PC3, and (D) PC4, comparing P. colorata individuals to the surrounding A. pusilla over distance. Decreases in log-likelihood scores indicate reduced similarities in leaf shape represented by the corresponding PC.

$180 \times 150 \mathrm{~mm}(300 \times 300 \mathrm{DPI})$ 